\title{
Loss of Seed-Dispersing Animals and Its Impacts on Humanity
}

\author{
Gilney Charll Santos ${ }^{1 *}$, Leonardo Silva Chaves ${ }^{2,3}$, Ulysses Paulino Albuquerque ${ }^{3}$
}

\begin{abstract}
Seed dispersal is a key ecological process for the maintenance of biodiversity and ecosystem functioning and is undoubtedly critical to the provision of valuable ecosystem benefits to humanity. However, the loss or population reduction of seed-dispersing animals, especially the medium and large ones, has increasingly compromised important ecological processes and associated ecosystem benefits. Thus, we aimed to present a brief review of the how the loss or reduction of seed-dispersing fauna affects the functioning of ecosystems and, consequently, humanity. We believe that this review provides new directions for future research in the field of conservation science that may contribute to policy initiatives and management and conservation plans.
\end{abstract}

Keywords: Ecosystem Benefits; Hunting; Defaunation; Ethnobiology; Ecosystem Functioning

\footnotetext{
1 Departamento de Ensino, Instituto Federal de Educação, Ciência e Tecnologia do Piauí, São Raimundo Nonato, PI, 64770000, Brasil.

2 Programa de Pós-graduação em Etnobiologia e Conservação da Natureza, Universidade Federal Rural de Pernambuco, Dois Irmãos, Recife, PE, 52171-900 Brasil.

${ }^{3}$ Laboratório de Ecologia e Evolução de Sistemas Socioecológicos (LEA), Centro de Biociências, Departamento de Botânica, Cidade Universitária, Recife, PE, 50670-901, Brasil.
}

* Corresponding author. $\mathrm{E}$ E-mail address: GCS (gilneycharll@hotmail.com), LSC (Ischaves@gmail.com), UPA (upa677@hotmail.com)

\section{INTRODUCTION}

The global loss of species of the fauna or the reduction of individuals within the populations, caused directly or indirectly by human influence, is known as defaunation, and is currently the subject of several researches due to the disastrous consequences driven by a possible and accelerated sixth mass extinction of animals on the planet (Young et al. 2016). It is estimated that since the beginning of the first navigations, 322 species of terrestrial vertebrates have been extinct, especially those of medium and large size, and that of the remaining populations, one in four has 
declined in abundance (Dirzo et al. 2014).

The consequences of defaunation, such as the disruption of ecological interactions and their effects on ecosystems, have been alerted for more than two decades through pioneering work such as that of Redford (1992) who coined the term "Empty Forest Syndrome". Interactions between animals and plants are fundamental to maintaining the ecological integrity of ecosystems and ecosystem services essential to humanity, such as seed dispersal. However, this important process and its benefits can be negatively affected by human actions such as illegal hunting, fragmentation and habitat loss (Galetti et al. 2016). In this article, we present a brief review, based on recent studies that examined how defaunation, especially of seed dispersers, affects the functioning of ecosystems and, consequently, humanity.

\section{CONSEQUENCES OF DEFAUNATION FOR THE FUNCTIONING OF ECOSYSTEMS AND FOR HUMANITY}

\section{Effects on the provision of ecosystem services}

Whether in local or global scale, hunting has been identified as one of the human actions that has contributed most to defaunation. Recent studies have shown quantitatively that this activity exerts a topdown effect on mammals populations. Koerner et al. (2016), for example, have shown a strong correlation between hunting intensity promoted by around 60 villages in northern Gabon and a defaunation gradient, evidenced by changes in diversity, relative abundance and composition of the mammal community. Because the various levels that make up an ecosystem are interdependent, changes in communities of hunted species can have system-wide consequences in a variety of ways. Feer and Boissier (2015) have demonstrated in French Guiana how the change in mammal abundance may be associated with changes in the community structure of dung beetles. They verified that in areas of intense defaunation, the richness of these beetles is $50 \%$ smaller than in areas intact or with moderate defaunation. The most evident negative impact was observed in the abundance of excavating species, which tends to generate cascade effects in the maintenance of ecosystem services mediated by these beetles, such as nutrient cycling and secondary seed dispersal (Feer and Boissier 2015).

A recent study carried out in the largest remnant of the Brazilian Atlantic Forest revealed that mammalian biomass declined up to $98 \%$ in places of intense hunting activity, and was 53 times smaller than in other non-fragmented neotropical forests (Galetti et al. 2016). The results of the research indicate that in regions of the Atlantic Forest where illegal hunting persists, animals such as peccaries (Tayassu pecari) and tapirs (Tapirus terrestris) are practically extinct locally, which tends to severely compromise the dispersion of large seed species, soil fertilization and forest regeneration, as there are no dispersers to replace these animals in their ecosystem functions (Galetti et al. 2016).

Areas of intense hunting activity may even maintain a similar number of mammals in relation to areas of lesser intensity. The difference is that in places where hunting is intense only small animals are practically found (Galetti et al. 2016). This is apprehensive, because without the large dispersers the large seed trees are in serious danger of disappearing, leading to the worsening of the greenhouse effect. In this context, when 31 communities of large 
Brazilian Atlantic Forest fragments $(\geq$ minimum area 1000 ha) were analyzed, the important contribution of large tree seeds for the storage of atmospheric carbon was observed (Bello et al. 2015). The authors concluded that trees with seeds larger than $12 \mathrm{~mm}$ wide present high carbon storage capacity, and that large dispersers are functionally connected to the planet's climate regulation, given their distinct link with these trees. The study found a robust support for the hypothesis that the absence of large trees (larger in stature and harder wood) would affect carbon stocks in defaunated tropical rainforests (Bello et al. 2015).

\section{Effects of increasing populations of small dispersers}

It is particularly important to analyze the consequences of defaunation on various aspects of plant dispersal and recruitment process, given the complexity of the interaction network of ecological processes. Pérez-Méndez et al. (2015), when verifying the effect of the size reduction of dispersers of Neochamaelea pulverulenta (Vent.) Erdtman, due to the selective extinction of lizards of the genus Gallotia in the Canary Islands, revealed that there were no substantial changes in the quantitative components of the seed dispersal. On the other hand, they recorded a significant reduction in recruitment of seedlings from outside the canopy and in the effective recruitment rate, as well as negative effects on seedling vigor (Pérez-Méndez et al. 2015). Unlike the scenario studied in the Canary Islands, plant-animal relationships are not always so exclusive, and the seeds of a plant species can be dispersed by different species of mammals, which makes this scenario even more complex. Paine et al. (2016), differently from the findings of
Galetti et al. (2016), have suggested that small and medium-sized mammals may play a more important role in maintaining the equilibrium of the tree community structure than large mammals. In addition to removing larger numbers of seeds than large mammals, these species cause a more intense impact on the beta diversity of the ecosystem (Paine et al. 2016).

However, despite the key role of small and medium-sized mammals for ecosystem balance, once large mammals are excluded, this ecological process does not seem to work very well. Areas with high rates of defaunation of large mammals have a predation rate that reaches two and a half times higher than in conserved areas (Galetti et al. 2015a). Although they are also efficient dispersers, the fundamental role of large mammals in this context seems to be related to the regulation of populations of smaller species. Another study carried out in areas of the Atlantic Forest evaluated the impacts on the community of small mammals, in a scenario of functional extinction of peccary (T. pecari ), that is, presenting a very low population. In addition to the reduction of diversity of small mammals, the moderation of competition for resource caused the abundance of small rodents in these areas to be twice that recorded in conserved areas (Galetti et al. 2015b). A similar imbalance was recorded in an area subjected to a hunting pressure gradient in northeastern Gabon. The consequences of this type of imbalance were observed in seed removal (increased by $63 \%$ ) and the subsequent seedlings settlement (reduced by $42 \%$ ) (Rosin and Poulsen 2016). Thus, in areas where medium and large dispersers are already extinct, the increase of the populations of small dispersers may collapse the dispersion of plant species of large seeds, such as the one presented above 
that occurred in Brazil with Astrocaryum aculeatissimum (Schott) Burret (Donatti et al. 2009).

\section{Changes in gene flow and microevo- lutionary changes}

Currently, one of the great interests of conservation scientists today is to understand how human actions that lead to defaunation can act as ecological drivers for the evolution of other organisms in the long term. In this context, Galetti et al. (2013) presented very interesting data, demonstrating how the extinction of large seed dispersing birds alters the evolutionary course of the associated plant species. The study compared the seed size distributions in 22 populations of Euterpe edulis Mart. in non-defaunated and defaunated areas of the Brazilian Atlantic Forest. It found a robust tendency for smaller seeds in defaunated areas. These areas were classified like that because large seed dispersal birds (with mean beak opening $>12 \mathrm{~mm}$ ), such as toucans (Ramphastos spp.), are extinct locally or functionally. The defaunation status of these areas represented a variance in seed size of approximately $40 \%$. In nondefaunated sites, seeds larger than $12 \mathrm{~mm}$ represented approximately $32 \%$ of the seeds produced by $E$. edulis populations. However, it was almost zero in defaunated locations. Thus, palm trees that produce smaller seeds have undergone a directional phenotypic selection in defaunated areas, which contrasts with the stabilizing selection observed in non-defaunated sites. According to the authors, seed size reduction of $E$. edulis probably occurred in the last 100 years, associated with the forest fragmentation caused by the human species (Galetti et al. 2013).

What is even more alarming is that the rapid defaunation of large seed dispersers is not only causing phenotypic changes in plant populations, but also in genotypic diversity and genetic pool structure, with unknown effects on long-term persistence, not only of one or another plant species, but of entire forest communities (Carvalho et al. 2016). However, it is important to note that seed dispersal by substitute or non-preferential agents is, for example, what ensures that even anachronistic plants (which used to be dispersed by the extinct megafauna) continue to exist (Guimarães et al. 2008). However, when large dispersers are lost, the species that depended on them for dispersal undergo changes in spatial distribution and even in gene flow. In a study involving 545 E. edulis seedlings, distributed among 19 sites (defaunated and non-defaunated areas) of two distinct biogeographical regions of the Brazilian Atlantic Forest, it was tested whether the loss of large seed dispersers could lead to microevolutionary changes in the species (Carvalho et al. 2016). The research has shown that large dispersers defaunation is the main driver of changes in allelic frequency between populations, and that individuals from defaunated areas present one and a half times greater genetic similarity than those found in non-defaunated areas. Thus, genetic erosion driven by defaunation has a long-lasting effect on microevolutionary processes, and may be crucial for the persistence of plants in a scenario of environmental and climatic changes (Carvalho et al. 2016).

\section{Potential effects on human health, food safety and the economy}

In addition to disrupting important ecological processes, defaunation may also affect human health by creating favorable 
conditions for the spread of diseases. One of the major concerns has been the growth of rodent abundance as a consequence of the selective elimination of large seed dispersers (Galetti et al. 2015b). Rodents cause substantial negative impacts on public health because they are important reservoirs of zoonoses. Currently, about 70 viral zoonoses are registered for rodents (Luis et al. 2013). Arenavirus (Charrel and de Lamballerie 2010) and Hantavirus (Schmaljohn and Hjelle 1997) are prominent due to their risk to human health.

A manipulative study conducted in Panama, developed to understand the role of diversity in the transmission of Hantavirus in rodents, has shown that the diversity of species in an ecosystem may contain the prevalence of infections in rodents by two distinct processes. The highest number of species can control the host population due to competition for resources or decrease the rate of interaction between individuals of the same species and, consequently, reduce the probability of transmission (Suzán et al. 2009). Despite the evidence of the role of species diversity as a buffer against pathogen transmission, there is still no consensus on this (see Young et al. 2013). Thus, it is appropriate to invest in empirical work that investigates the effect of defaunation on transmission of zoonoses through rodents.

Another important issue is that the defaunation of large seed dispersers has direct effects on food security, since it is estimated that more than one billion people depend on wild meat for subsistence in the poorest regions of the planet (Brashares et al. 2014). In African forests, for example, this resource tends to decline by around $80 \%$ over the next five decades (Fa et al. 2003). In addition, the population loss or reduction of dispersant animals may still compromise the supply of fruits and other plant structures used for food or commerce by extractivist communities, due to the limited dispersion of seeds and regeneration of the plant species targeted by extractivism. In this context, for Caryocar coriaceum Wittm., a plant species of food and economic importance for the extractive communities of northeastern Brazil, a low percentage of seed removal (maximum of $11 \%$ ) was found. It evidences a population decline of dispersers of this species (Santos et al. 2016), probably due to illegal hunting that occurs in the studied region (Silva Neto et al. 2016). Thus, not only would the supply of animal or plant products be compromised by defaunation, but also the region's economy (generation of employment and income), causing ecological and social impacts difficult to reverse.

\section{SYNTHESIS AND PERSPECTIVES}

1. The loss of seed-dispersing animals can seriously compromise the functioning of ecosystems and the provision of valuable ecosystem goods and services to humanity, such as seed dispersal, nutrient cycling, climate regulation, diseases control, food supply and employment and income generation;

2. In addition to promoting a population bloom of small rodents, which may affect public health and ecosystem balance, the defaunation of large seed dispersers can also alter the evolutionary course of the associated plants, compromising the persistence of these plants in a scenario of environmental changes;

3. The researches that deal with the issue of defaunation are typically of biological nature, and most suggest an increase of public policies that aim at a rigorous inspection with the purpose of combating illegal hunting; 
4. We believe that imposing sanctions against a practice historically exercised by the human species, without exploring the possible underlying causes of the issue, such as local characteristics, culture, poverty and hunger would be a great mistake;

5. We emphasize the need for ethnobiology studies guided by hypotheses, to better understand these patterns and their respective effects.

\section{ACKNOWLEDGEMENTS}

The authors are grateful to FACEPE (Fundação de Amparo à Ciência e Tecnologia do Estado de Pernambuco) for the doctoral scholarship granted to LSC and CNPq (Conselho Nacional de Desenvolvimento Científico e Tecnológico) for the research productivity scholarship granted to UPA.

\section{REFERENCES}

Bello C, Galetti M, Pizo MA, Magnago LFS, Rocha MF, Lima RAF, Peres CA, Ovaskainen O, Jordano P (2015) Defaunation affects carbon storage in tropical forests. Science Advances 1(11): 1-10.

Brashares JS, Abrahms B, Fiorella KJ, Golden CD, Hojnowski CE, Marsh RA, McCauley DJ, Nuñez TA, Seto K, Withey L (2014) Wildlife decline and social conflict. Science 345(6195): 376-378.

Carvalho CS, Galetti M, Colevatti RG, Jordano P (2016) Defaunation leads to microevolutionary changes in a tropical palm. Scientific Reports 6(31957): 1-8.

Charrel RN, de Lamballerie X (2010) Zoonotic aspects of arenavirus infections. Veterinary Microbiology 140(3-4): 213-220.

Dirzo R, Young HS, Galetti M, Ceballos G, Isaac NJB, Collen B (2014) Defaunation in the Anthropocene. Science 345(6195): 401-406.

Donatti Cl, Guimarães PR, Galetti M (2009) Seed dispersal and predation in the endemic Atlantic rainforest palm Astrocaryum aculeatissimum across a gradient of seed disperser abundance. Ecological Research 24: 1187-1195.

Fa JE, Currie D, Meeuwig J (2003) Bushmeat and food security in the Congo basin: Linkages between wildlife and people's future. Environmental Conservation 30(1): 7178.

Feer F, Boissier O (2015) Variations in dung beetle assemblages across a gradient of hunting in a tropical forest. Ecological Indicators 57: 164-170.

Galetti M, Guevara R, Côrtes MC, Fadini R, Von Matter S, Leite AB, Labecca $F$, Ribeiro $T$, Carvalho CS, Collevatti RG, Pires MM, Guimarães Jr PR, Brancalion PH, Ribeiro MC, Jordano $P$ (2013) Functional extinction of birds drives rapid evolutionary changes in seed size. Science 340(6136): 1086-1090.

Galetti M, Bovendorp RS, Guevara R (2015a) Defaunation of large mammals leads to an increase in seed predation in the Atlantic forests. Global Ecology and Conservation 3: 824-830.

Galetti M, Guevara R, Neves CL, Rodarte RR, Bovendorp RS, Moreira M, Hopkins III JB, Yeakel JD (2015b) Defaunation affect population and diet of rodents in Neotropical rainforests. Biological Conservation 190: 2-7.

Galetti M, Brocardo CR, Begotti RA, Hortenci L, Rocha-Mendes F, Bernardo CSS, Bueno RS, Nobre R, Bovendorp RS, Marques RM, Meirelles F, Gobbo SK, Beca G, Schmaedecke G, Siqueira $T$ (2016) Defaunation and biomass collapse of mammals in the largest Atlantic forest remnant. Animal Conservation 20(3): 270-281.

Guimarães PR JR, Galetti M, Jordano P (2008) Seed dispersal anachronisms: rethinking the fruits extinct megafauna ate. Plos One 3(3): 113.

Koerner SE, Poulsen JR, Blanchard EJ, Okouyi J, Clark CJ (2016) Vertebrate community composition and diversity declines along a defaunation gradient radiating from rural villages in Gabon. Journal of Applied Ecology 54(3): 805-814.

Luis AD, Hayman DTS, O'Shea TJ, Cryan PM, Gilbert AT, Pulliam JRC, Mills JN, Timonin ME, 
Willis CKR, Cunningham AA, Fooks AR, Rupprecht CE, Wood JLN, Webb CT (2013) A comparison of bats and rodents as reservoirs of zoonotic viruses: are bats special? Proceedings of the Royal Society B 280(1756): 1-9.

Paine CET, Beck H, Terborgh J (2016) How mammalian predation contributes to tropical tree community structure. Ecology 97(12): 3326-3336.

Pérez-Méndez N, Jordano P, Valido A (2015) Downsized mutualisms: Consequences of seed dispersers' body-size reduction for early plant recruitment. Perspectives in Plant Ecology, Evolution and Systematics 17(2): 151159.

Redford KH (1992) The Empty Forest. BioScience 42(6): 412-422.

Rosin C, Poulsen JR (2016) Hunting-induced defaunation drives increased seed predation and decreased seedling establishment of commercially important tree species in an Afrotropical forest. Forest Ecology and Management 382: 206-213.

Santos GC, Schiel N, Araújo EL, Albuquerque UP (2016) Caryocar coriaceum (Caryocaraceae) diaspore removal and dispersal distance on the margin and in the interior of a Cerrado area in Northeastern Brazil. Revista de Biología Tropical 64(3): 1117-1127.

Schmaljohn C, Hjelle B (1997) Hantaviruses: A Global Disease Problem. Emerging Infectious
Diseases 3(2): 95-104.

Silva Neto BC, Nascimento ALB, Schiel N, Alves RRN, Souto A, Albuquerque UP (2016) Assessment of the hunting of mammals using local ecological knowledge: an example from the Brazilian semiarid region. Environment, Development and Sustainability 1-19.

Suzán G, Marcé E, Giermakowski JT, Mills JN, Ceballos G, Ostfeld RS, Armién B, Pascale JM, Yates TL (2009) Experimental evidence for reduced rodent diversity causing increased hantavirus prevalence. Plos One 4(5): 1-7.

Young H, Griffin RH, Wood CL, Nunn CL (2013) Does habitat disturbance increase infectious disease risk for primates? Ecology Letters 16(5): 656-663.

Young HS, McCauley DJ, Galetti M, Dirzo R (2016) Patterns, Causes, and Consequences of Anthropocene Defaunation. Annual Review of Ecology, Evolution, and Systematics 47: 333358.

Received: 06 April 2017

Accepted: 19 September 2017

Published: 29 September 2017 